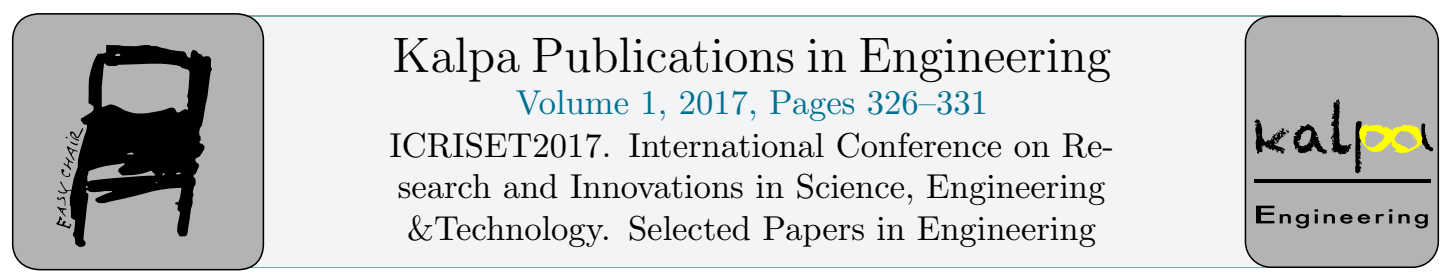

\title{
Location Optimization of Fixture for Gearbox Housing
}

\author{
Mihir T. Dhobi ${ }^{\text {a }}$, Ronak R. Patel ${ }^{\mathrm{b}}$, Shashank P. Joshi ${ }^{\mathrm{c}}$ \\ ${ }^{\mathrm{a}}$ M.E. Machine Design, ${ }^{\mathrm{b}}$ Assistant Professor, ${ }^{\mathrm{c}}$ Associate Professor, \\ Department of Mechanical Engineering, BVM Engineering College, \\ V. V. Nagar, Gujarat, India.
}

\begin{abstract}
An ideal fixture should maximize the stability and locating accuracy of workpiece and also minimize deformations during operation. The present work aims at designing a machining fixture for boring and face milling operations of helical gear boxes and attempts to provide a solution which gives accurate workpiece control. These gear boxes are manufactured as per DIN 3664 with class 6 . Generally, the dimensional and geometric tolerances for features are of the order of 20 microns. Hence, the fixture design demands accurate workpiece control. The accurate workpiece control can be obtained by determining the position of locators and clamps which yields minimum deflection of the workpiece. In this paper, optimization of the positions of the locators and clamps is carried out using Genetic Algorithm (GA) with ANSYS Parametric Design Language (APDL). The prediction of the positions of the locators and clamps is done by using Artificial Neural Network (ANN) and Response Surface Methodology (RSM) which is used as input data for Genetic Algorithm. A systematic process is developed to minimize the workpiece elastic deformation and to optimize the locators and clamping positions using Genetic Algorithm and Finite Element Analysis. The procedure developed can be used by industry to develop fixture for any complex geometry of workpiece.
\end{abstract}

Keywords: Optimization; Fixture; Genetic Algorithm; ANN; RSM

\section{Introduction}

The A fixture locates and holds the workpiece. The location and holding system are developed to ensure the required workpiece control. There is a point contact between the workpiece locators and clamps. This leads to the contact forces which affects workpiece displacement and locating accuracy of workpiece ${ }^{[2]}$. Thus, to minimize the workpiece deformation during machining, the amount of clamping force, the position of the locators and clamps and the number of locators and clamps are to be optimized ${ }^{[3]}$. The research work has been carried out for simple components, not for 
real life problem. Hence, it is decided to carry out the present work for the real life problem. The present work aims at designing a machining fixture for boring and face milling operations of helical gear boxes used in industries as shown in Fig. 1. Weight of gearbox is approximately 1.4 tons. Gear box housing is made up of casting (FG 250) material.
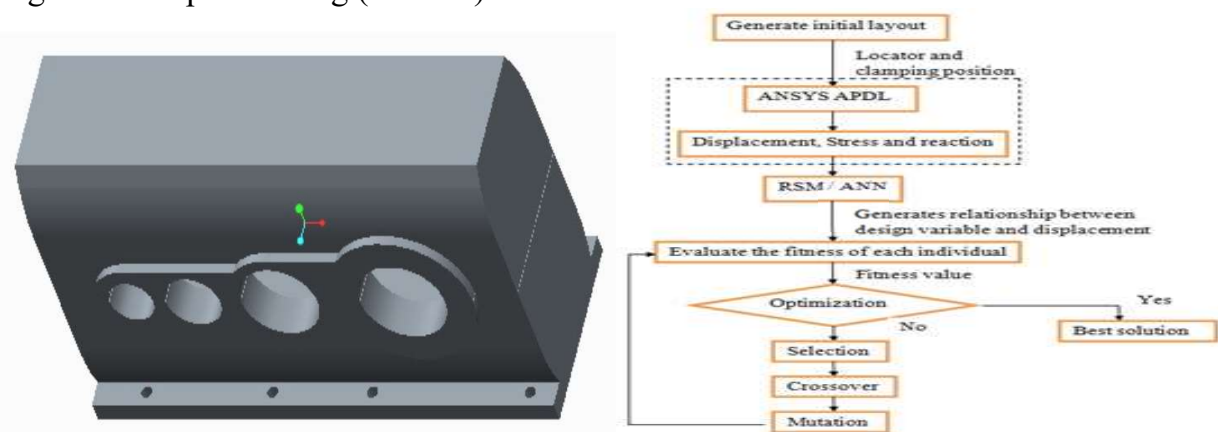

Figure 1: 3D model of gear box housing

Figure 2: Flow chart of Methodology for Optimization

\section{Problem Description}

Design of a machining fixture involves application of 3-2-1 location principle. But 3-2-1 location principle cannot give the information regarding the exact position of locators and clamps. The present work aims at designing a machining fixture for boring and face milling operations of helical gear boxes and attempts to provide a solution which gives accurate workpiece control. These gear boxes are made as per DIN 3664 with class 6. Generally, the dimensional and geometric tolerances for features are of the order of 20 microns. Hence, the fixture design demands accurate workpiece control. The accurate workpiece control can be obtained by determining the position of locators and clamps which yields minimum deflection of the workpiece. This can be achieved using Genetic Algorithm with the help of RSM or ANN. In the present work, a systematic process is developed to minimize the workpiece elastic deformation and to optimize the locators and clamping positions using Genetic Algorithm and Finite Element Analysis.

\section{Methodology for Optimization}

Fig. 2 shows the flow chart of methodology for optimization. GA is suitable for optimizing complex systems with large number of design variables. The problem with fixture design optimization is nonlinear because there does not exist direct analytical relationship between the objective function and design variables i.e. between deformation and fixture parameters (locator and clamp positions and clamping forces ${ }^{[1]}$. Thus, there is a need to predict the fixture layout to minimize the maximum elastic deformation of the workpiece during machining ${ }^{[5]}$. The position of the fixturing elements is predicted by two techniques. (1) Response Surface Methodology (2) Artificial neural network

\subsection{Machining and Clamping Forces}

Operations that are carried out during machining are boring, face milling and drilling. For all these operations machining forces are calculated based on the technical specification of the machine in the industry. Among these operations, the maximum force is acting in face milling operation, which is in order of $4577.83 \mathrm{~N}$ (Radial force $=2517.8 \mathrm{~N}$ and Axial force $=1831.132 \mathrm{~N}$ ). Thus, this force is 
taken for calculating clamping forces by considering it as a worst case. The required clamping force to hold the workpiece is $11215.68 \mathrm{~N}$.

\subsection{Generation of Initial Layout for Locators and Clamps Position}

Fig. 3 shows the gear box housing with fine meshing. To predict the relationship between objective function and design variables, initial layout are generated. The elastic deformation of the workpiece is the objective function and the position of the locators and clamps are the design variables for the system. There are three locators and two clamps in each and every possible fixture layout. The values of all the five design variables are assumed to stand within a specified range. Elastic deformation of the workpiece is determined using FEA for different layouts. The position of all the fixturing elements and the deformation are used as input for both RSM and ANN to predict the fixture layout.

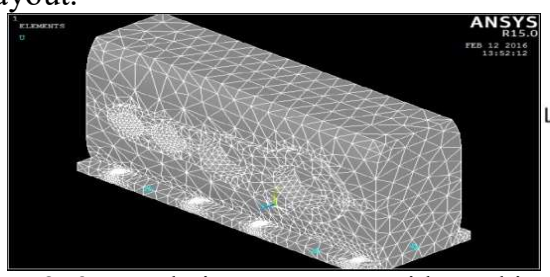

Figure 3: 3D workpiece geometry with meshing

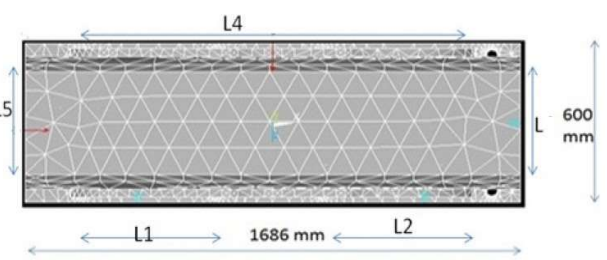

Figure 4: Top view of the workpiece

The coordinate values of the position of all fixturing elements (design variables) are determined using random generation method within their respective ranges for various layouts and the corresponding maximum workpiece elastic deformation is obtained using FEA in ANSYS APDL R15.0. Table 1 shows the 20 sets of fixture layouts.

Table 1: Design of 20 sets of fixture layout

\begin{tabular}{|l|l|l|l|l|l|}
\hline \multirow{2}{*}{ No } & \multicolumn{5}{|c|}{ Design variables } \\
\cline { 2 - 6 } & $\mathbf{L 1 ( m m )}$ & $\mathbf{L 2 ( m m )}$ & $\mathbf{L 3 ( m m )}$ & $\mathbf{L 4 ( m m )}$ & L5(mm) \\
\hline 1 & 230.1236 & 1060.3963 & 90.3691 & 1438.059 & 512.5963 \\
\hline 2 & 595.0588 & 1462.8530 & 450.1290 & 1272.7350 & 357.5741 \\
\hline. &. &. &. &. &. \\
\hline $\mathbf{2 0}$ & $\mathbf{5 5 9 . 3 4 9 0}$ & $\mathbf{1 3 8 0 . 6 3 8 0}$ & $\mathbf{2 9 4 . 6 3 9 1}$ & $\mathbf{9 0 0 . 6 3 9 2}$ & $\mathbf{3 3 2 . 1 0 2 7}$ \\
\hline
\end{tabular}

From these 20 layouts any one can be selected to check deformation. For highlighted Sr. no 20, deformation is checked using ANSYS APDL. Fig. 4 shows the workpiece fixture system is made up of three locators L1, L2 and L3 and two clamps L4 and L5. The ranges of values for the design variables in $\mathrm{X}$ direction are as follows: (Bottom left corner is taken as origin)

$210.75<\mathrm{L} 1<632.25,1053.75<\mathrm{L} 2<1475.25,75<\mathrm{L} 3<525,210.75<\mathrm{L} 4<1475.25,75<\mathrm{L} 5<525$

Position of locators and clamps for the $\mathrm{Y}$ direction is ranges from 16.25 to 48.75 for all variables.

\subsubsection{Boundary Conditions}

The locator's nodes are fully constrained where as the clamps nodes are constrained only in the transverse direction (X and $\mathrm{Y}$ ). Clamping forces are applied in the normal direction ( $\mathrm{Z}$ direction) at the clamp nodes. For all 20 sets, deformation and vonmises stress is obtained. This deformation and vonmises stress are further used to obtain the relationship between deformation and position of locators and clamps. 


\subsection{Response Surface Methodology}

Response Surface Methodology is suitable for complex systems with large number of design variables. RSM requires a set of designed experiments to determine a response. This method is easy to interpolate and apply, although less is known about the process. $\mathrm{x}_{1}, \mathrm{x}_{2}, \mathrm{x}_{3}, \mathrm{x}_{4}$ and $\mathrm{x}_{5}$ are the five independent variables and $\mathrm{Y}$ is response. Then it can be represented as a function as follows ${ }^{[4]}$

$\mathrm{Y}=\mathrm{f}\left(\mathrm{x}_{1}, \mathrm{x}_{2}, \mathrm{x}_{3}, \mathrm{x}_{4}, \mathrm{x}_{5}\right)+\mathrm{e} \quad$,Where $\mathrm{e}=$ error

The second order RSM model can be described as follows ${ }^{[4]}$

$\mathrm{Y}=\beta_{0}+\sum_{i=0}^{k} \beta \mathrm{ixi}+\sum_{i=0}^{k} \beta \mathrm{iixi}+\sum_{i j}^{k} \beta \mathrm{iixixj}+\mathrm{e}$

Where $\beta \mathrm{i}(\mathrm{i}=0,1, \ldots, \mathrm{p})$ are coefficients which are required to be find out and e represents a normally distributed random error that represents for all source of variability ${ }^{[4]}$. The fitted equation is represented by ${ }^{[4]}$

$\mathrm{Y}=\mathrm{E}($ Def - e)

$\mathrm{Y}=\beta_{0}+\sum_{i=0}^{k} \beta \mathrm{ixi}+\sum_{i=0}^{k} \beta \mathrm{iixi}+\sum_{i j}^{k} \beta \mathrm{iixixj}$

Where $\beta_{0}$ is the estimator of intercept, $\beta_{1}, \beta_{2}, . ., \beta_{\mathrm{k}}$ are linear terms, $\beta_{11}, \beta_{22}, \ldots, \beta_{\mathrm{kk}}$ are quadratic terms and $\beta_{12}, \beta_{13}, . ., \beta_{\mathrm{k}-1, \mathrm{k}}$ are the second order interaction terms ${ }^{[4]}$.

The response function expressing the deformation can be expressed as,

Deformation $=\mathrm{f}\left(\mathrm{L}_{1}, \mathrm{~L}_{2}, \mathrm{~L}_{3}, \mathrm{~L}_{4}, \mathrm{~L}_{5}\right)$.

For five factors, the polynomial could be represented as follows

Def $=\beta_{0}+\beta_{1} L_{1}+\beta_{2} L_{2}+\beta_{3} L_{3}+\beta_{4} L_{4}+\beta_{5} L_{5}+\beta_{11} L_{21}+\beta_{22} L_{22}+\beta_{33} L_{23}+\beta_{44} L_{24}+\beta_{55} L_{25}+\beta_{12} L_{1} L_{2}+$

$\beta_{13} \mathrm{~L}_{2} \mathrm{~L}_{3}+\beta_{14} \mathrm{~L}_{1} \mathrm{~L}_{4}+\beta_{15} \mathrm{~L}_{1} \mathrm{~L}_{5}+\beta_{23} \mathrm{~L}_{2} \mathrm{~L}_{3}+\beta_{24} \mathrm{~L}_{2} \mathrm{~L}_{4}+\beta_{25} \mathrm{~L}_{2} \mathrm{~L}_{5}+\beta_{34} \mathrm{~L}_{3} \mathrm{~L}_{4}+\beta_{35} \mathrm{~L}_{3} \mathrm{~L}_{5}+\beta_{45} \mathrm{~L}_{4} \mathrm{~L}_{5}$

The values of the coefficient of the polynomial were calculated by regression method.

\subsubsection{Result of RSM}

A MATLAB program has been developed to find out the coefficients $\left(\beta_{0}, \beta_{1}, \ldots\right.$ etc) of eq. (1). The output of the MATLAB program gives the relationship between the positions of locators and clamps (i.e. design variables) and deformation. The prediction error in RSM is $2 \%$.

Deformation $=0.70859+0.009 \mathrm{~L}_{1}+0.006 \mathrm{~L}_{2}-0.0399 \mathrm{~L}_{3}-0.063 \mathrm{~L}_{4}+0.0335 \mathrm{~L}_{5}-0.0010 \mathrm{~L}_{1}^{2}-$ $1.02345 * 10^{-5} \mathrm{~L}_{2}^{2}-0.0002 \mathrm{~L}_{3}^{2}+9.0213 * 10^{-6} \mathrm{~L}_{4}^{2}+0.0001 \mathrm{~L}_{5}^{2}+9.210^{*} 10^{-6} \mathrm{~L}_{1} \mathrm{~L}_{2}+0.00019 \mathrm{~L}_{2} \mathrm{~L}_{3}+$ $0.0001236 \mathrm{~L}_{1} \mathrm{~L}_{4}-0.00041 \mathrm{~L}_{1} \mathrm{~L}_{5}-0.00012 \mathrm{~L}_{2} \mathrm{~L}_{3}+7.273 * 10^{-6} \mathrm{~L}_{2} \mathrm{~L}_{4}+1.06^{*} 10^{-6} \mathrm{~L}_{2} \mathrm{~L}_{5}+4.1804 * 10^{-6} \mathrm{~L}_{3} \mathrm{~L}_{4}-$ $0.00019 \mathrm{~L}_{3} \mathrm{~L}_{5}+1.0019 * 10^{-6} \mathrm{~L}_{4} \mathrm{~L}_{5}$

\subsection{Artificial Neural Networks}

To train and test the network, back propagation learning rule is adopted. The actual output of the network is compared with the target value and the errors are fed back to adjust the weights between the layers for improving the performance ${ }^{[5]}$. The workpiece fixture system is made up of three locators L1, L2 and L3 and two clamps L4 and L5. Hence, the input layer composes of five neurons to represent five fixture elements and the output layer consists of one neuron to represent the workpiece elastic deformation. One hidden layer is considered that has the same number of neurons as the input layer i.e. five neurons ${ }^{[3]}$. In the present work, Architecture, training and testing is carried out in MATLAB The overall value of regression is 0.92581 . The prediction error in ANN is around $7.4 \%$.

\subsection{Comments on RSM and ANN method}

RSM and ANN methods are used to predict the maximum elastic deformation of workpiece. For various fixture layouts, RSM and ANN performances have been compared by simulating the workpiece elastic deformation. The prediction error in RSM is $2 \%$ while in ANN is $7.4 \%$. Thus, RSM 
gives more satisfactory results. Hence, the resultant relationship generated using RSM becomes objective function for Genetic Algorithm.

\section{Optimization using Genetic Algorithm}

\subsection{Optimization Model for Fixture Design}

The mathematically model for the optimization problem is as follows;

$\operatorname{Min}\left(\max \left(\left|\Delta_{1}\right|,\left|\Delta_{2}\right|, \ldots,\left|\Delta_{\mathrm{n}}\right|\right)\right)=1,2, \ldots, \mathrm{n}$

A feasible fixture layout has to satisfy the following four constraints ${ }^{[2]}$ :

(1) The normal compressive stress at the contact point must be below the compressive yield stress of the workpiece material. $\left(\sigma_{\mathrm{c}} \leq \sigma_{\mathrm{y}}\right)$

(2) The maximum shear stress must be below that allowable limit. $\left(\tau_{\max } \leq \sigma_{\mathrm{y}} / 2\right)$

(3) The Von mises stress must be below that of yield strength of the materials. $\left(\sigma_{\mathrm{von}} \leq \sigma_{\mathrm{y}}\right)$

(4) The position of fixture element-workpiece contact points must be in the candidate region; this constraint is automatically covered in the stage of limits used in the co-ordinate values.

\subsection{Output of GA}

A MATLAB program is made to find out the optimum solution of fixture layout. The output of the MATLAB program gives the optimum values for the position of locators and clamps which yields to minimum elastic deformation. The optimum value of the fixturing elements is as follows.

L1-516.517 mm, L2-1302.2392 mm, L3-300.3389 mm, L4-850.0021 mm, L5-306.2369 mm

\subsection{Validation of GA using ANSYS APDL}

For validation of optimum fixture layout ANSYS APDL R15.0 is used. The optimum fixture layout is further given to ANSYS as shown in Table 2. Deformation in the initial fixture layout was around $0.0249 \mathrm{~mm}$ as shown in Fig. 5. After that the optimized fixture layout which is generated from GA is given into ANSYS for further validation. Deformation in the improved fixture layout is around $0.00139 \mathrm{~mm}$ as shown in Fig. 6. Also, the vonmises stress in the initial fixture layout was around $55.13 \mathrm{~N} / \mathrm{mm}^{2}$, which is reduced to around $2.79 \mathrm{~N} / \mathrm{mm}^{2}$.

Table 2: Comparison of results of GA optimization and ANSYS

\begin{tabular}{|c|c|c|c|}
\hline & $\begin{array}{l}\text { Initial } \\
\text { layout }\end{array}$ & $\begin{array}{l}\text { Improved layout } \\
\text { (GA optimization) }\end{array}$ & Validation in ANSYS \\
\hline Deformation (mm) & 0.0249 & 0.00151 & 0.00139 \\
\hline Vonmises stress $\left(\mathrm{N} / \mathrm{mm}^{2}\right)$ & 55.13 & 3.03 & 2.79 \\
\hline 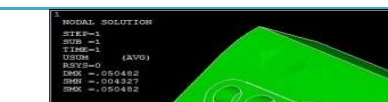 & & 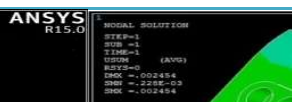 & $\overline{A N S Y S .0}$ \\
\hline
\end{tabular}

Figure 5: Deformation in initial fixture layout Figure 6: Deformation in optimum fixture layout 


\section{Discussion}

(1) Deformation and vonmises stress in the initial fixture layout was around $0.0249 \mathrm{~mm}$ and $55.13 \mathrm{~N} / \mathrm{mm}^{2}$ respectively as shown in Fig. 5. Deformation and vonmises stress in the optimized fixture layout which is generated from GA is around $0.00151 \mathrm{~mm}$ and 3.03 $\mathrm{N} / \mathrm{mm}^{2}$ as shown in Table 2 .

(2) The optimized fixture layout which is generated from GA is feeded to ANSYS APDL for validation. Deformation and vonmises stress obtained from ANSYS is around $0.00139 \mathrm{~mm}$ and $2.79 \mathrm{~N} / \mathrm{mm}^{2}$ respectively as shown in Fig. 6.

(3) After optimization, deformation and vonmises stress is reduced by $93.9 \%$ and $94.5 \%$ respectively. Results obtained from ANSYS APDL are very close to that of the results obtained from GA. The variation in deformation between GA and APDL is about $7.94 \%$ and vonmises stress between GA and APDL is about $7.9 \%$.

(4) Vonmises stress obtained by GA and ANSYS are well within the permissible stress of the workpiece. As the deformation value obtained is very low, dimensional control of the workpiece can be achieved in the range of $0.02 \mathrm{~mm}$.

\section{Conclusion}

(1) RSM and ANN can be used for predicting the relationship between elastic deformation and positions of locators and clamps. For the present work, the prediction error of RSM is $2 \%$ and ANN 7.4\%.

(2) GA is the most effective tool to optimize the location of locators, so as to minimize elastic deformation and stresses during the operation.

(3) The optimize location yields minimum deformation $(0.00152 \mathrm{~mm})$ and maximum stress $\left(2.79 \mathrm{~N} / \mathrm{mm}^{2}\right)$ which indicates that a robust solution is obtained using the developed method.

(4) A systematic process is developed to minimize the workpiece elastic deformation and to optimize the locators and clamping positions using Genetic Algorithm and Finite Element Analysis. The procedure developed can be used by industry to develop fixture for any complex geometry of workpiece.

\section{References}

Weifang Chen. (2008) Deformation control through fixture layout design and clamping force optimization, The International Journal of Advanced Manufacturing Technology,

K. Siva Kumar. (2010) Genetic algorithm based deformation control and clamping force optimisation of workpiece fixture system, International Journal of Production Research.

Selvakumar, S., K. P. Arulshri, K. P. Padmanaban, and K. S. K. Sasikumar. (2013) Design and optimization of machining fixture layout using $A N N$ and DOE, The International Journal of Advanced Manufacturing Technology.

R. Narayanasamy. (2008) Application of response surface methodology for predicting bend force during air bending process in interstitial free steel sheet, The International Journal of Advanced Manufacturing Technology.

M. Vasundara, K.P. Padmanaban, M. Sabareeswaran, M. RajGanesh. (2012) Machining fixture layout designfor milling operation using FEA, ANN and RSM, mathematical and numerical methods in simulating \& modeling, Procedia Engineering 38, 1693 - 1703 